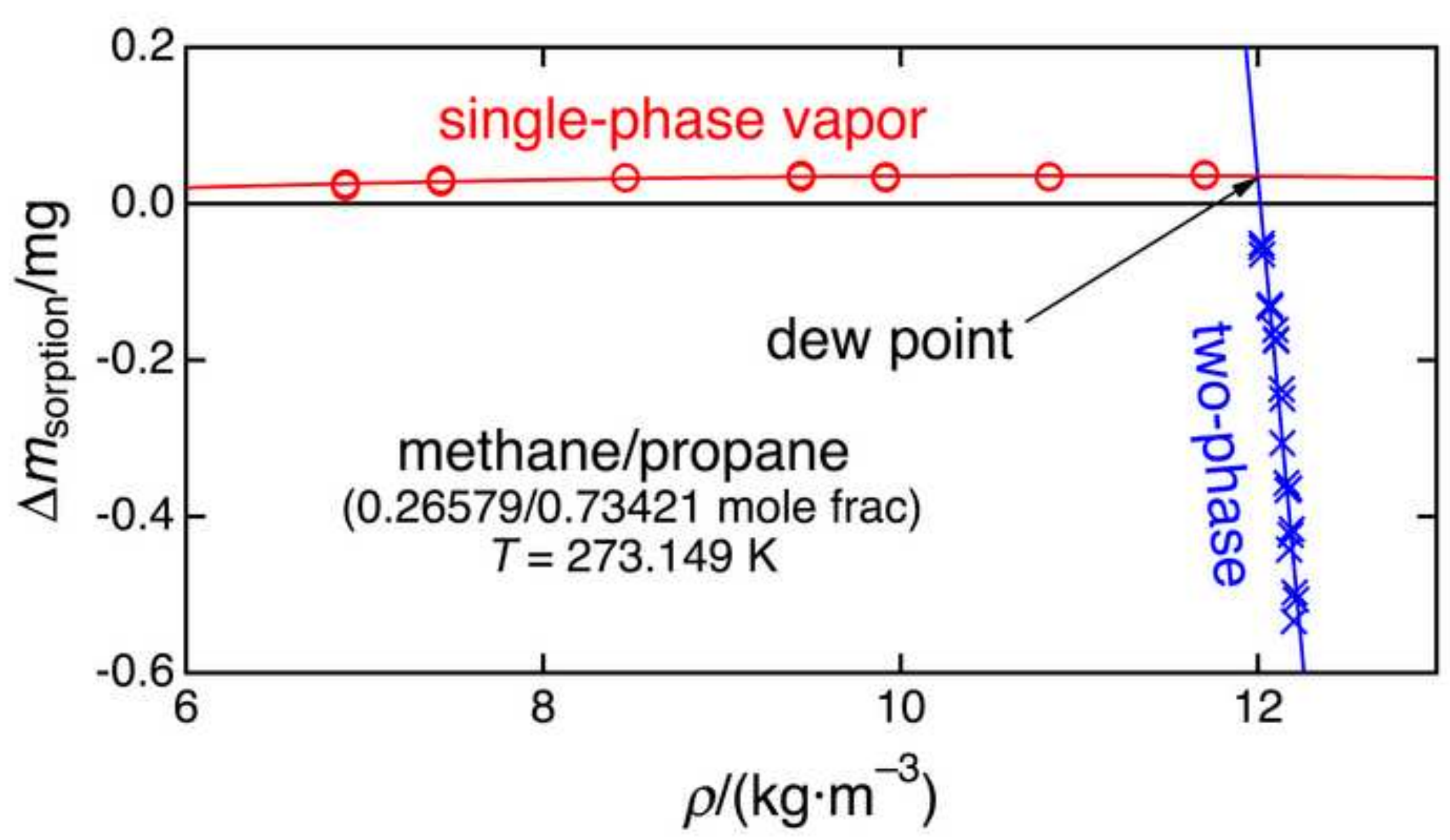




\title{
Application of a two-sinker densimeter for phase-equilibrium measurements: A new technique for the detection of dew points and measurements on the (methane + propane) system ${ }^{1}$
}

\author{
Mark O. McLinden ${ }^{2}$, Markus Richter ${ }^{3}$ \\ Applied Chemicals and Materials Division, National Institute of Standards and Technology \\ 325 Broadway, Mailstop 647.07, Boulder, Colorado 80305 USA
}

\begin{abstract}
We explore a novel method for determining the dew-point density and dew-point pressure of fluid mixtures and compare it to traditional methods. The $(p, \rho, T, x)$ behavior of three (methane + propane) mixtures was investigated with a two-sinker magnetic suspension densimeter over the temperature range of ( 248.15 to 293.15$) \mathrm{K}$; the measurements extended from low pressures into the two-phase region. The compositions of the gravimetrically prepared mixtures were $(0.74977$, 0.50688, and 0.26579) mole fraction methane. We analyzed isothermal data by: (1) a "traditional" analysis of the intersection of a virial fit of the ( $p$ vs. $\rho$ ) data in the single-phase region with a linear fit of the data in the two-phase region; and (2) an analysis of the adsorbed mass on the sinker surfaces. We compared these to a traditional isochoric experiment. We conclude that the "adsorbed mass" analysis of an isothermal experiment provides an accurate determination of the dew-point temperature, pressure, and density. However, a two-sinker densimeter is required.
\end{abstract}

Keywords: adsorption; dew point; gas density; measurement; methane; propane

\section{Introduction}

To understand the phase behavior of fluid mixtures and to develop models that precisely describe the phase boundary between liquid and vapor, accurate experimental data are essential.

\footnotetext{
${ }^{1}$ Contribution of the National Institute of Standards and Technology. Not subject to copyright in the United States.

${ }^{2}$ Corresponding author. Tel.: +1 303497 3580; fax: +1 303497 6682. Email addresses: markm@boulder.nist.gov (M. O. McLinden); M.Richter@thermo.rub.de (M. Richter)

${ }^{3}$ Present address: Lehrstuhl für Thermodynamik, Ruhr-Universität Bochum, D-44780 Bochum, Germany
} 

mixtures. These can be divided into two broad categories: (1) methods that detect the presence of condensate, such as chilled mirrors [1]-[2], other optical methods [3] and the magneticsuspension balance [4] or (2) methods that detect a change in slope of one measured quantity versus another, such as the isochoric technique [5]-[6], quartz crystal microbalances [7]-[8] microwave re-entrant cavities [9]-[10] and the acoustic spherical resonator [11]-[12]. For many of these techniques, the accuracy is unfortunately rather poor. Compared to properties for mixtures in the homogeneous vapor region, which can achieve nearly the accuracy of the corresponding properties for pure fluids, the experimental uncertainty for properties on the saturation line (e.g., dew-point pressures) can be much higher. Moreover, accurate data for dewpoint densities of fluid mixtures are virtually nonexistent. A significant contribution to the uncertainty arises from the uncertainty in the mixture composition; most authors used an analytic method, which involved taking samples for a composition measurement (often by gas chromatography). A minority of authors used a synthetic method with gravimetrically prepared mixtures. While the synthetic approach can yield good results with careful calibration of the composition-analysis method, the synthetic approach is generally more accurate.

A notable example of careful investigation of the dew point available in the literature is the work of May et al. [4], who conducted accurate $(p, \rho, T)$ measurements with gas mixtures when approaching and crossing the dew line, thus, locating the dew-point pressure and density. They used a modified commercial magnetic-suspension balance with three stable suspension positions. Two sinkers could be weighed in different suspension positions within the fluid of interest. For investigations at dew-point conditions, measurements were carried out along isochores. Measurements began at a temperature above the expected dew point and went into the two-phase region with decreasing temperature. In contrast to the original two-sinker densimeter technique of Kleinrahm and Wagner [13], [14], the bottom sinker could not be weighed separately, and this limited the accuracy of their results. Nevertheless, they detected the presence of condensate in a quantitative manner, rather than merely detecting a change in slope. They prepared their mixture samples gravimetrically (i.e., using a "synthetic method"). 
Against this background, the major objective of the present work was to investigate a new technique for the accurate determination of dew-point pressures and dew-point densities of binary mixtures. Binary mixtures were chosen because state-of-the-art models for multicomponent mixtures (for example, the GERG-2008 equation of state for natural gas of Kunz and Wagner [15]) are only fitted in terms of the constituent binary pairs. The instrument utilized was the highly accurate two-sinker densimeter of the National Institute of Standards and Technology (NIST)[16]. We selected the binary system (methane + propane) because the twophase region fits well within the operating temperature and pressure range of the densimeter. Moreover, this system is of industrial importance so that resulting data would be useful for improving mixture models. The vapor-phase $(p, \rho, T, x)$ behavior and virial coefficients of three (methane + propane) mixtures were reported by us previously [17].

The two-sinker density measurement method, as developed by Kleinrahm and Wagner [13], [14], is the most accurate technique to determine densities of fluids in the gas phase. Thus, we assumed that this technique would also be suitable for the determination of mixture dew-point densities. We build on the work of May et al. [4], but also extend it in several ways; in particular, we carry out measurements along isotherms, and we will argue that this gives more information and lower uncertainties compared to an isochoric method. Furthermore, our "true" two-sinker instrument allows microgram-level detection of condensate.

In this work, the densimeter was utilized with sinkers that were optimized for accurate density measurements. The intention of this paper is to explore different methods to approach the dew line and to determine dew-point pressures as well as dew-point densities of three (methane + propane) mixtures. An additional novel method is suggested which is a modification of the twosinker technique. However, this is the topic of a companion paper [18].

\section{Experimental}

\subsection{Apparatus Description}

The present measurements utilized a two-sinker densimeter with a magnetic suspension coupling. This type of instrument applies the Archimedes (buoyancy) principle to provide an absolute determination of the density. This general type of instrument is described by Wagner and Kleinrahm [14], and our instrument is described in detail by McLinden and Lösch-Will [16]. Briefly, two sinkers of nearly the same mass and same surface area, but very different volumes $($ ratio $\approx 3.7)$, were each weighed with a high-precision balance while they were immersed in a fluid of unknown density. The fluid density $\rho$ is given by 


$$
=\frac{\left(\begin{array}{lll}
m_{1} & m_{2}
\end{array}\right)\left(\begin{array}{ll}
W_{1} & W_{2}
\end{array}\right)}{\left(\begin{array}{ll}
V_{1} & V_{2}
\end{array}\right)},
$$

where $m$ and $V$ are the sinker mass and volume, $W$ is the balance reading, and the subscripts refer to the two sinkers. Each sinker had a mass of approximately $60 \mathrm{~g}$; one was made of tantalum (which we designate as sinker $1, V_{1} \approx 3.6 \mathrm{~cm}^{3}$ ) and the other of titanium (sinker 2, $V_{2} \approx 13.3 \mathrm{~cm}^{3}$ ). The surface area of each sinker was approximately $41.5 \mathrm{~cm}^{2}$. A magnetic suspension coupling transmitted the gravity and buoyancy forces on the sinkers to the balance, thus isolating the fluid sample from the balance. Two additional calibration masses (designated as "tare" and "cal"), which were placed directly on the balance pan, were also weighed as part of each density determination. In comparison with other buoyancy techniques, the main advantage of the two-sinker method, as developed by Kleinrahm and Wagner [13] is that systematic errors in the weighing and from other sources approximately cancel. Moreover, the two-sinker technique leads to lower uncertainties for measurements at low densities compared to a singlesinker instrument.

\subsection{Analysis of Sorption/Condensation}

Equation (1) must be expanded to account for perturbations to the magnetic suspension coupling due to the magnetic effects of the measuring cell and of the fluid being measured, i.e., to account for the so-called "force-transmission error;" this analysis is presented by McLinden et al. [19]. Briefly, they wrote out equations listing all of the forces for each of the four weighings required for a density determination (i.e., the two sinkers and the two calibration masses). This yielded a system of four equations that were solved for the four unknowns of fluid density $\rho_{\text {fluid, }}$ a balance calibration factor $\alpha$, a parameter $\beta$ related to the balance tare (i.e., the magnets and other elements of the system that are suspended from the balance for all the weighings), and a parameter $\phi$ that characterizes the efficiency of the magnetic suspension coupling. The difference of the value of $\phi$ from 1 indicates the magnitude of the force transmission error. This analysis yields the fluid density

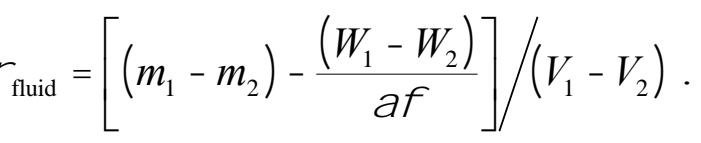

where the balance calibration factor and coupling parameter are given by

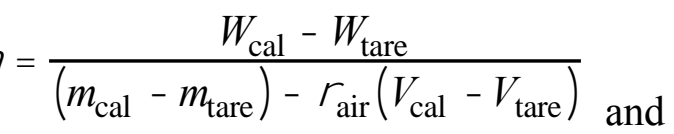




$$
=\frac{\left(W_{1} /\right)}{m_{1} \quad \text { fluid } V_{1}}
$$

and the tare parameter is

$$
\left.=\frac{W_{\text {cal }}}{m_{\text {cal }}} \quad{ }_{\text {air }} V_{\text {cal }}\right) .
$$

The subscripts "cal" and "tare" refer to the calibration masses, and $\rho_{\text {air }}$ is the density of the gas under the balance hood. Note that equation (2) reduces to equation (1) when $\alpha=1$ and $\phi=1$. Equations (2 to 5) yield the fluid density, including an accounting of the force-transmission error, in terms of directly measured quantities.

A key assumption in the analysis of McLinden et al. [19] was that all quantities were constant over the time necessary to complete the weighings for a density determination, which was about 12 minutes. In addition, the sinker masses were assumed to be constant and equal to the values determined prior to their installation in the densimeter. For measurements in homogenous liquid or gaseous states, these assumption apply. But for measurements near the dew line, sorption onto the surface of the sinkers can affect the effective sinker masses, and inside the two-phase region, condensation of sample onto one or both sinkers will change the effective sinker masses. Thus, the above equations must be modified.

As in the original analysis of McLinden et al. [19], the weighings of the sinkers and calibration masses can be written as

$$
\begin{aligned}
& W_{1}=\left[\left\{\begin{array}{ll}
m_{1} & \text { fluid } \\
1
\end{array}\right\}+\right] \text {, } \\
& \left.W_{2}=\left[\begin{array}{ll}
m_{2} & \text { fluid }
\end{array} V_{2}\right\}+\right] \text {, } \\
& W_{\text {cal }}=\left[m_{\text {cal }} \quad{ }_{\text {air }} V_{\text {cal }}+\right] \text {, and }
\end{aligned}
$$

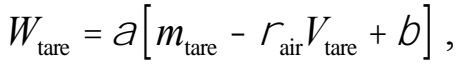

where the parameters $\alpha$ and $\beta$ are as defined above. However, now we will solve for the sinker masses in terms of the other variables:

$$
m_{1}=m_{1}+m_{1, \text { sorp }}=\frac{W_{1} /{ }_{\text {fluid }} V_{1}}{,}
$$




$$
m_{2}=m_{2}+m_{2, \text { sorp }}=\frac{W_{2} /+{ }_{\text {fluid }} V_{2}}{,}
$$

where the prime indicates that the mass may be different from the original determination because of adsorbed material present on the sinker, i.e., $\delta m_{1, \text { sorp }}$ or $\delta m_{2, \text { sorp: }}$ :

$$
\begin{aligned}
& m_{1, \text { sorp }}=\frac{W_{1} /+_{\text {fluid }} V_{1}}{m_{1} \text { and }} \\
& m_{2, \text { sorp }}=\frac{W_{2} /+_{\text {fluid }} V_{2}}{m_{2} .}
\end{aligned}
$$

Depending on the different surface characteristics of the two sinkers and any temperature gradients in the measuring cell, varying amounts of sample will adsorb or condense on each of the sinkers. Taking the difference of Eqs 12 and 13 yields a measure of the adsorbed mass:

$$
m_{\text {sorption }}=\left(\begin{array}{cc}
m_{2, \text { sorp }} & m_{1, \text { sorp }}
\end{array}\right)=\frac{W_{2}}{W_{1}}+{ }_{\text {fluid }}\left(\begin{array}{ll}
V_{1} & V_{2}
\end{array}\right)+\left(\begin{array}{ll}
m_{1} & m_{2}
\end{array}\right) .
$$

Note that $\Delta m_{\text {sorption }}$ is not the mass of material adsorbed onto sinker 2, but rather the mass of material adsorbed onto sinker 2 minus that adsorbed onto sinker 1. It is not possible to solve for $\delta m_{1, \text { sorp }}$ and $\delta m_{2 \text {,sorp }}$ separately because the remaining equations would not be sufficient to solve for the fluid density.

Equation (14) gives a quantitative estimate of sorption effects, but at the expense of "using" one of the four available equations, i.e., equations $(6-9)$. The parameters $\alpha$ and $\beta$ "use" two additional equations, leaving only one equation, but two unknowns: $\rho_{\text {fluid }}$ and $\phi$. This is the situation one has with a single-sinker densimeter, and we apply the analysis of McLinden et al. [19] for that type of instrument. That analysis demonstrated that the coupling factor can be divided into apparatus and fluid-specific contributions; $\phi_{0}$ is the value of $\phi$ in vacuum and is the apparatus contribution. Furthermore, $\phi$ is related to the fluid density and the specific magnetic susceptibility of the fluid $\chi_{\mathrm{s}}$ so that

$$
={ }_{0}+\frac{\mathrm{s}}{\mathrm{s} 0} \frac{\text { fluid }}{0}
$$

where $\rho_{0}=1000 \mathrm{~kg} \cdot \mathrm{m}^{-3}$ and $\chi_{\mathrm{s} 0}=10^{-8} \mathrm{~m}^{3} \cdot \mathrm{kg}^{-1}$ are reducing constants and $\varepsilon_{\rho}$ is an apparatusspecific constant. For a single-sinker densimeter $\varepsilon_{\rho}$ must be determined by a tedious calibration involving measurements with different sinkers installed at different times. For our two-sinker densimeter, however, $\varepsilon_{\rho}$ can be determined from measurements in the homogeneous vapor 
region, including measurements made along an isotherm just prior to entering the two-phase region. The value of $\chi_{\mathrm{s}}$ is calculated as the mole-fraction-weighted average of the molar purefluid susceptibilities given by [20]; the specific susceptibility is obtained by dividing by the molar mass of the mixture. The value of $\phi_{0}$ is determined by weighing made with the measuring cell under vacuum; in any event, this test is carried out regularly to check for possible contamination of the sinkers and to reset the zero of the pressure transducers.

The result is that we have obtained a quantitative measure of sorption/condensation effects, which is a very sensitive indicator of the onset of condensation, as will be discussed in section 3 . However this has come at the expense of effectively changing our two-sinker densimeter to a single-sinker instrument. In other words, one of the sinkers serves as the "density sinker" and the other serves as a "sorption sinker."

\subsection{Preparation of the Sample Mixtures}

The gas mixtures were prepared gravimetrically. The components are described in table 1 . We used the materials as received, but we did confirm their purity with our own analysis. The compositions of the three prepared mixtures are given in table 2. The maxcondentherm for the three mixtures ranged from $292.1 \mathrm{~K}$ to $346.6 \mathrm{~K}$. They were prepared in aluminum gas cylinders of approximately $10 \mathrm{~L}$ internal volume. The sample mass was determined by a double substitution weighing design as described by Harris and Torres [21], with a nearly identical "tare" or reference cylinder serving as the main substitution mass. Further details are provided by Richter and McLinden [17].

The three sample cylinders were loaded to pressures corresponding to the dew-point pressure at $T=293.15 \mathrm{~K}$, which were $p=6 \mathrm{MPa}$ for the $(0.74977$ methane +0.25023 propane $)$ mixture, $p=1.9 \mathrm{MPa}$ for the $(0.50688$ methane +0.49312 propane $)$ mixture, and $p=1.2 \mathrm{MPa}$ for the $(0.26579$ methane +0.73421 propane $)$ mixture. There may have been a small amount of liquid in the sample cylinders after filling, but they were heated continuously to $T>313 \mathrm{~K}$ for the duration of the testing to ensure that only single-phase vapor was present. Due to sorption effects, the composition of the sample in the measuring cell could be different from that calculated from the sample masses loaded into the sample cylinder. This is discussed in section 4.3 .

\subsection{Experimental Procedures}

The vapor-phase densities of the (methane + propane) system was previously studied by Richter and McLinden [17], and a subset of their data is analyzed here. Reference [17] reports 
measurements along 27 isotherms for the three mixtures. Of those, 16 were entirely in the homogenous vapor region. The remaining 11 isotherms extended into the two-phase region and are analyzed here. (The two-phase values were not reported by Richter and McLinden [17] and are included here in the Supplementary Data.) In addition to the measurements along isotherms, two pseudo-isochores were also measured for the $(0.26579$ methane +0.73421 propane $)$ mixture.

Measurements were carried out along isotherms at $T=(248.15,273.15$, and 293.15$) \mathrm{K}$ for each of the three mixtures; except that $T=293.15 \mathrm{~K}$ was above the maxcondentherm for the $(0.74977$ methane +0.25023 propane) mixture. Each isotherm started at a low pressure well within the homogeneous vapor region; the pressure was increased in steps of (0.1 to 0.2) MPa by cycling a pair of pneumatically controlled valves that trapped a volume of sample between them. After an equilibration time of $30 \mathrm{~min}$., three replicate density determinations were made. As the dewpoint pressure was approached, the pressure was increased in smaller steps by cycling the pneumatic valves a single time. The isotherm was terminated when the data indicated that the system had entered the two-phase region.

The standard procedure between measurements on the different isotherms was to evacuate the measuring cell for (10 to 30 ) $\mathrm{min}$. This was followed by a purging cycle consisting of filling the measuring cell to approximately $50 \%$ of the dew-point pressure; this sample remained inside the cell for $2 \mathrm{~min}$; the cell was then evacuated for $2 \mathrm{~min}$; this routine was repeated three times before filling in the sample for the next isotherm. For several of the isotherms, however, the measuring cell was evacuated for several hours between fillings.

For the isochoric experiments the measuring cell was equilibrated at a temperature approximately $2 \mathrm{~K}$ above the target dew-point temperature; it was then filled to a pressure approximately $1 \%$ above the expected dew-point pressure at the target temperature. Additional equilibration time was allowed, and then the electrical heating to the measuring cell and shields was turned off, and the temperature subsequently decreased at the rate of approximately $0.25 \mathrm{~K} \cdot \mathrm{h}^{-1}$. A density determination was carried out every $30 \mathrm{~min}$ until the data indicated that the system had entered the two-phase region.

\section{Results}

\subsection{Analysis of ( $p, \rho, T, x)$ Data Along Isotherms}

The isothermal data will be analyzed in multiple ways. The basic approach is to fit a simple function (e.g., a linear or a quadratic equation) to the data points in the single-phase and twophase regions; the dew point is given by the intersection. Figure 1 shows the results for the 
isotherm at $T=273.149 \mathrm{~K}$, with a composition of ( 0.26579 methane +0.73421 propane $)$, which is typical for our results. For the plot of pressure versus density (figure 1a), the vapor-phase data are well fitted by a quadratic function, which is equivalent to a virial expansion truncated at the second virial coefficient. There is a discontinuity in slope at the dew point, and the two-phase values are fitted reasonably well by a straight line. The intersection of these fits yields a dewpoint density of $12.026 \mathrm{~kg} \cdot \mathrm{m}^{-3}$.

A plot of $\Delta m_{\text {sorption }}$ versus density (figure 1 b) shows a very small $(<0.03 \mathrm{mg}$ ), nearly constant value of $\Delta m_{\text {sorption }}$ in the single-phase region. Upon entering the two-phase region, there is a dramatic change in slope. The dew-point density given by this intersection is $12.003 \mathrm{~kg} \cdot \mathrm{m}^{-3}$. The effect is very clear despite the small magnitude of $\Delta m_{\text {sorption }}$ (less than $0.6 \mathrm{mg}$ ). The negative values of $\Delta m_{\text {sorption }}$ indicate that more sample collected on sinker 1 (the tantalum sinker, which is located at the top of the measuring cell) compared to sinker 2 (the titanium sinker, which is located below the tantalum sinker at the bottom of the cell). This result may be due to temperature gradients in the measuring cell: for operation at sub-ambient temperatures, cooling is applied to the top of the cell, and thus, the top of the cell was cooler than the bottom. The greater adsorption on the tantalum sinker could also be the result of different surface characteristics for the two sinkers. The original sinkers in this densimeter were both gold plated, as described by McLinden and Lösch-Will [16]. Those sinkers have been replaced by tantalum and titanium sinkers of a "monolithic" design that were milled from solid bar stock (as opposed to the original sinkers, which had "lifting pins" that were welded into the main body of the sinkers). The new sinkers were polished to a similar surface roughness, but they were not plated. The effect of the different metals on adsorption effects will be the subject of future work.

All of the densities plotted in the figures and reported in the Supporting Data (including those labeled as "two-phase" or "transition") were measured for the vapor phase; however, they do not necessarily represent the actual state of the vapor sample in the measuring cell. The sinker masses and volumes are affected by the adsorbed/condensed sample that has collected on the sinkers. The composition of the vapor-phase composition is affected by sample condensing not only onto the surfaces of the sinkers but also on the walls of the measuring cell. The changing composition is largely responsible for the increased slope of the two-phase data observed in the plot of pressure versus density (Fig 1a). But, in this work, we extrapolate the two-phase data to the dew point where the effects of the condensed mass and the changing composition vanish.

Similar data for the isotherm at $T=248.151 \mathrm{~K}$, with a composition of $(0.50688$ methane + 0.49312 propane), are plotted versus pressure in figure $2 \mathrm{a}$. The results are very similar to those shown in figure $1 \mathrm{~b}$, except that the data in the two-phase region show a larger scatter. This may 
be due to two factors. At the low pressures measured for this isotherm, the pressure transducer is at the lower portion of its range and its relative resolution is lower. Also the uncertainty in pressure due to hydrostatic head effects is proportionally larger compared to pressures in the homogeneous vapor region. (This effect is discussed further in section 4.1.) By comparison, the data plotted versus density, figure $2 b$, show less scatter. For these reasons, it may be preferable to find the dew-point density by the intersection of the $\Delta m_{\text {sorption }}$ versus density data (figure $2 \mathrm{~b}$ ) and calculate the dew-point pressure by extrapolating the virial fit of the data in the single-phase region to the dew-point density. The three replicates for the $(0.50688$ methane +0.49312 propane) mixture at $T=273.15 \mathrm{~K}$, for example, show less variation when the $p_{\text {dew }}$ is calculated by evaluating the virial fit of single-phase vapor data at $\rho_{\text {dew }}$ compared to the $\Delta m_{\text {sorption versus } p}$ analysis (total variations of $0.90 \%$ and $2.03 \%$, respectively).

The analysis methods shown in figures 1 and 2 show a distinct change in slope at the dew point, and the dew points calculated from each of them are nearly the same. A case where the analysis of $\Delta m_{\text {sorption }}$ is clearly better than the "traditional" analysis of pressure versus density is shown in figure 3, for the isotherm at $T=293.147 \mathrm{~K}$ for the $(0.50688$ methane +0.49312 propane $)$ mixture. Here only a small range of pressure was measured in the two-phase region, and the twophase points in the pressure versus density plot (figure 3a) show only a very small deviation from

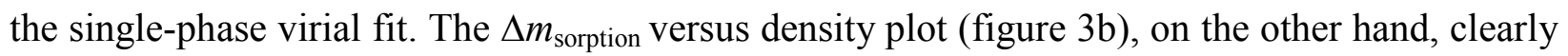
shows the transition to the two-phase region. It would have been difficult to correctly identify the two-phase points in the absence of the $\Delta m_{\text {sorption }}$ data.

The dew-point densities and pressures resulting from the different methods of analysis are given in table 3 for the "traditional analysis" of the 11 (methane + propane) isotherms. Table 4 gives

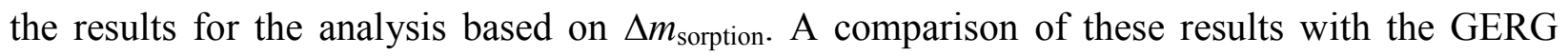
model is given in table 3 (for the "traditional analysis") and in table 4 and figure 4 (for the "sorption analysis"), where we give the relative deviation in the dew point

$$
\text { ,dew }=100 \frac{\left(\begin{array}{ll}
\text { dew,exp } & \text { dew,GERG }
\end{array}\right)}{\text { dew,GERG }} \text {, }
$$

where $\gamma$ is either dew-point pressure or density. There is a clear systematic trend observed in figure 4; the deviations become increasingly negative as the dew-point density increases. (The same trend applies to increasing temperature. Since we measured at the same temperatures for each mixture, we plot the deviations versus density to better separate the isotherms on the plot.) There is better agreement with the GERG model for the $(0.74977$ methane +0.25023 propane $)$ mixture compared to the mixtures with higher propane contents. Richter and McLinden [17] 
observed the same trend for the single-phase vapor densities. Detailed data for each of the measured $(p, \rho, T, x)$ points are given in the Supplementary Data.

\subsection{Analysis of $(p, \rho, T, x)$ Data Along Quasi-Isochores}

The results for the isochoric experiment for the $(0.26579$ methane +0.73421 propane $)$ mixture at a density of approximately $12.1 \mathrm{~kg} \cdot \mathrm{m}^{-3}$ are shown in figure 5 . The "traditional" analysis of pressure versus temperature (figure 5a) shows a distinct change in slope at the dew point $\left(T_{\text {dew }}=\right.$ $273.409 \mathrm{~K}, p_{\text {dew }}=0.6722 \mathrm{MPa}$ ). But in contrast to typical isochoric experiments, which are carried out in a simple closed vessel, we were measuring density continuously as the measuring cell was cooled. A plot of the pressure versus density (figure 5b) shows a distinct transition region (plotted as $\Delta$ ) between the homogenous vapor phase (plotted as $\circ$ ) and the two-phase region (plotted as + ). We postulate that this transition region corresponds to "capillary condensation," which is also known as "precondensation;" the exploration of this region is the subject of a companion paper [18].

The density for this "isochoric" experiment is seen to vary (figure 5b). It increased very slightly (relative variation of less than $0.04 \%$ ) as the temperature decreased in the homogeneous vapor phase. This is due to contraction of the measuring cell with decreasing temperature and pressure and to migration of sample between the measuring cell and the pressure transducer, which was located outside the measuring cell, and which was thermostatted at $T=313 \mathrm{~K}$. In the two-phase region, however, the density decreased a total of $1.52 \%$ as the cell cooled from $T=273.378 \mathrm{~K}$ to $T=272.765 \mathrm{~K}$. Here, the less-volatile propane preferentially condensed out, leaving the vapor phase enriched in the less-dense methane. The total variation in $\Delta m_{\text {sorption }}$ for the isochoric experiment was less than $0.050 \mathrm{mg}$; this was much less than in the isothermal experiments, and so it was not feasible to carry out the $\Delta m_{\text {sorption }}$ analysis, as was done for the isothermal experiments. The small magnitude of $\Delta m_{\text {sorption }}$ may be the result of the way the isochoric experiment was carried out. The temperature was continuously decreasing due to heat loss from the measuring cell; thus, the cell cooled faster than the sample inside it. Sample would thus adsorb/condense on the walls of the measuring cell rather than on the sinkers, which were the slowest to cool down.

The dew-point densities and pressures are given in table 5 for the two isochores measured. A comparison of these results with the GERG equation of state is given in table 5 and figure 4 . The deviations for the isochoric experiments are in close agreement with the isothermal experiments at similar temperatures. Detailed information for each of the measured $(p, \rho, T, x)$ points are given in the Supplementary Data. 


\subsection{Comparison to Literature Data}

Kunz et al. [22] provide a comprehensive review of the literature data for the (methane + propane) system existing as of 2004. Dr. Eric Lemmon of NIST [23] made his database of mixture data available to us, and it included five additional sources not referenced by Kunz et al. (these were Kalra and Robinson [24], Powers et al. [25], Cutler [26] Roof and Baron [27], and Stoeckli and Stateley [28]). The only recent source was that of May et al. [29] In total, there are 21 literature sources with 787 data points at saturation; these cover the full range of composition and temperatures spanning nearly the full range from the triple point to critical point of propane $(85.5 \mathrm{~K}$ to $369.9 \mathrm{~K})$. Most of the sources report VLE (typically $(p, T, x)$ or $(p, T, x, y))$ data, and in figure 6, we plot deviations in the saturation pressure (either bubble-point pressure or dewpoint pressure, depending on what was reported). Although the data are wide-ranging, the distinct observation from figure 6 is that the scatter in the data (both between data sets and, often, within sets) is quite large; the average RMS deviation between the data and the GERG model is $4.1 \%$. This figure shows that the present data are well inside the "cloud" of literature data.

May et al. [29] recently reported careful $(p, T, x, y)$ measurements on the (methane + propane) system and also evaluated the literature data and recommended the "best" literature data sets, which were those of Webster and Kidnay [30] and Price and Kobayashi [31]. These recommended sets, along with the present data and those of May et al. [29] are plotted in black and red in figure 6; there is much better internal consistency between these sets compared to the literature data overall.

Three sources report dew-point densities, and these data are compared to the GERG model in figure 7. In this figure, we plot the difference between the experimental dew-point temperature and the $T_{\text {dew }}$ calculated from the GERG model as a function of the composition. We plot $\Delta T_{\text {dew }}$ rather than $\Delta \rho_{\text {dew }}$ because a significant fraction of the literature data are either near the maxcondentherm (where a small difference in temperature results in a large difference in dewpoint density) or in the retrograde-condensation region (where there are two solutions for $\rho_{\text {dew }}(T)$ ). The data of Sage et al. [32] and Reamer et al. [33], from 1934 and 1950, respectively, show very large deviations, ranging from $-21.2 \mathrm{~K}$ to $9.3 \mathrm{~K}$. Both of these sources used an isochoric method combined with a graphical analysis to interpolate the raw experimental results. The more recent (2001) data from May et al. [4] show much smaller deviations of $0.71 \mathrm{~K}$ to $0.94 \mathrm{~K}$ in $T_{\text {dew. }}$. The deviations in our current data range from $-0.05 \mathrm{~K}$ to $1.60 \mathrm{~K}$. This figure illustrates both the scarcity of dew-point density data for mixtures, and the large scatter in many of the literature sources. 
The most meaningful comparison of our current data with the literature data for dew-point density is for our measurement on the $(0.74977$ methane +0.25023 propane $)$ mixture at $T=273.152 \mathrm{~K}$, which has $\Delta T_{\mathrm{dew}}=0.40 \mathrm{~K}$. This compares to the results of May et al. [4] on a (0.7931 methane +0.2069 propane) mixture at $T=(284.6 \pm 0.2) \mathrm{K}$, which has $\Delta T_{\text {dew }}=0.71 \mathrm{~K}$. The difference is slightly outside the mutual uncertainties, but the two points are at slightly different compositions and temperatures.

There are additional data sets that report densities in the homogeneous vapor phase for the (methane + propane) system. These were compared to the single-phase portion of the present data in Richter and McLinden [17]. The scatter observed for the vapor-phase densities (i.e., figure 7 in [17]) was somewhat smaller than that seen here in figure 6. There was, however, generally good consistency between the sets reporting the interaction second virial coefficient $B_{12}$ (see figure 9 in [17]), which further highlights the difficulties of measurements at the dew point compared to single-phase states.

Considering the literature data presented in figures 6 and 7, we conclude that the GERG model fitted the data as well as was possible given the large scatter in the data.

\section{Uncertainty Analysis}

The uncertainty sources include the temperature, pressure, density, and composition. For measurements in single-phase states, these have been discussed in previous publications and are summarized in sections 4.1 through 4.3 . The dew point was determined by the intersection of single-phase and two-phase data, and the uncertainties in the dew-point density and dew-point pressure involve additional terms, which are discussed in section 4.4.

\subsection{Uncertainty in temperature, density, and pressure}

McLinden and Lösch-Will [16] provide an analysis of uncertainties for gas-phase measurements, and McLinden and Splett [34] provide a further detailed uncertainty analysis for this instrument. Those results are summarized here. The standard uncertainty in the density was

$$
\frac{u(\quad)}{\mathrm{kg} \cdot \mathrm{m}^{-3}}=\left[\{16\}^{2}+\left\{0.20\left|\left(\begin{array}{ll}
T / \mathrm{K} & 293
\end{array}\right)\right|\right\}^{2}+\{0.63 p / \mathrm{MPa}\}^{2}\right]^{0.5} \frac{10^{6}}{\mathrm{~kg} \cdot \mathrm{m}^{-3}}+0.0010
$$

where the term in brackets is from the uncertainties in the volumes of the two sinkers, and the final, constant term includes all other uncertainties. We added to this uncertainty the standard deviations actually observed in the multiple balance readings made over the 12 minutes 
necessary to complete a single density determination. For the present work, the uncertainty in the density measurement itself (for single-phase states) was a maximum of $0.0077 \mathrm{~kg} \cdot \mathrm{m}^{-3}$; the largest relative uncertainty was $0.10 \%$ at the lowest measured density, $\rho=1.66 \mathrm{~kg} \cdot \mathrm{m}^{-3}$. The uncertainties in two-phase states were higher because of sample condensing onto the sinkers.

The SPRT used to measure the temperature of the mixture was calibrated in our laboratory on ITS-90 from $T=(83$ to 505$) \mathrm{K}$ by use of fixed-point cells. The standard uncertainty of the temperature, including the uncertainty in the fixed-point cells, drift in the SPRT and in the standard resistor, and any temperature gradients, is $3 \mathrm{mK}$. Oscillations over time were separately accounted for and were $1 \mathrm{mK}$ or less. This temperature uncertainty impacts gas densities at the level of approximately $0.0010 \%$.

For the isochoric experiments, the temperature of the measuring cell was continuously decreasing. This resulted in greatly increased temperature gradients across the cell compared to the isothermal experiments. This effect was estimated to increase the standard temperature uncertainty to $0.050 \mathrm{~K}$.

The uncertainty of the pressure measurement arises from three sources: (1) the calibration of the transducers, (2) the repeatability and temporal drift of the transducers, and (3) the uncertainty in the hydrostatic head correction. The pressure transducers were calibrated with a gas-operated piston gauge. This calibration was done in situ by connecting the piston gauge to the sample port of the filling and pressure manifold. We estimated the standard uncertainty due to the calibration and drift of the transducers to be $\left(20 \times 10^{-6} \cdot p+0.025 \mathrm{kPa}\right)$ for the low-range transducer $\left(p_{\max }=2.7 \mathrm{MPa}\right)$ and $\left(20 \times 10^{-6} \cdot p+0.06 \mathrm{kPa}\right)$ for the mid-range transducer $\left(p_{\max }=6.9 \mathrm{MPa}\right)$. The complete data tables in the Supplementary Data of this paper indicate which transducer was used for a given measurement.

Because we are concerned here primarily with pressures near the dew point, the uncertainty due to the hydrostatic head correction is substantially larger than is usually the case for this instrument. The connecting line from the measuring cell to the pressure transducer exited at the bottom of the measuring cell and was in contact with the isothermal shield (which was maintained at a temperature $1 \mathrm{~K}$ lower than the cell temperature) before connecting with the pressure manifold, which was maintained at $T=313 \mathrm{~K}$. Because of this arrangement, it is likely that liquid was present in a portion of the pressure line, but the location of the liquid-vapor interface was uncertain. We estimate the standard uncertainty in the hydrostatic head correction corresponds to a $5 \mathrm{~cm}$ height of liquid in equilibrium with the vapor in the measuring cell, corresponding to a maximum pressure uncertainty of $0.24 \mathrm{kPa}$. 
The combined standard uncertainty in pressure is

$$
u_{c}(p)=\left\{u^{2}\left(p_{\text {transducer }}\right)+[(p)]^{2}+\left[u(h) g\left(\begin{array}{ll}
\text { liq } & \text { vap }
\end{array}\right)\right]^{2}\right\}^{1 / 2}
$$

The first term on the right-hand side represents the uncertainty due to the pressure transducer, $\sigma(p)$ is the standard deviation of the replicate pressure readings taken over the 12 minutes of a density determination, $g$ is the local acceleration of gravity, $\rho_{\text {liq }}$ and $\rho_{\text {vap }}$ are the liquid and vapor sample densities in the pressure line (as calculated with the GERG EOS), and $u(h)$ is the uncertainty in the height of the liquid/vapor interface (i.e., $5 \mathrm{~cm}$ ). The combined standard uncertainty in pressure ranged from $(0.05$ to 2.0$) \mathrm{kPa}$ for the present measurements.

\subsection{Uncertainty in composition arising from mixture preparation}

For a gas mixture, a considerable fraction of the overall density uncertainty is due to uncertainty in the composition. To first order, the molar density of a vapor mixture is constant for a given $T$, $p$, and $x$, or equivalently, the mass density is proportional to the molar mass, so that the uncertainty in density due to uncertainties in the composition is proportional to the uncertainty in $M$, the molar mass of the mixture. The uncertainty in $M$ due to uncertainties in the gravimetric preparation is given by

$$
u\left(M_{\text {grav }}\right)=\left\{\sum_{j=1}^{n}\left[\frac{\sum_{i=1}^{n} \frac{m_{i}}{M_{i}}\left(\sum_{i=1}^{n} m_{i}\right) / M_{j}}{\left(\sum_{i=1}^{n} \frac{m_{i}}{M_{i}}\right)^{2}} u\left(m_{j}\right)\right]^{2}\right\}^{0.5},
$$

where the $M_{\mathrm{i}}$ are the molar masses of the components, and the $m_{\mathrm{i}}$ represents the mass of each of the components loaded into the sample cylinder. With an uncertainty of $0.010 \mathrm{~g}$ for each of the component masses, $u\left(M_{\text {grav }}\right)$ ranged from $(0.00016$ to 0.00185$) \mathrm{g} \cdot \mathrm{mol}^{-1}$ for the mixtures studied here. A derivation of equation (19) is presented in the Supporting Information of Richter and McLinden [17]. The uncertainty in $M$ for a binary mixture can be converted to an equivalent uncertainty in the composition $u(x)$ by

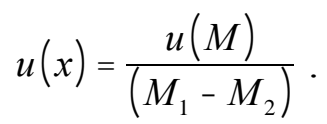


This analysis is exact for ideal gases, and it is a good approximation for real gases at low pressures. In any event, it is adequate for assigning uncertainties, which are inherently approximate.

Given the very high purity of our starting materials, the uncertainty in $M_{i}$ due to impurities in the components was negligible. The standard uncertainty due to the uncertainties in the atomic masses of carbon (from fossil fuels) and hydrogen (Wieser et al. [35]) was approximately $0.0003 \mathrm{~g} \cdot \mathrm{mol}^{-1}$.

\subsection{Uncertainty in composition arising from sorption effects}

A further source of uncertainty in the composition arose from sorption of sample onto the sinkers, the inner walls of the measuring cell, sample cylinder, filling lines, etc. In other words, the composition in the measuring cell was not necessarily a simple ratio of the component masses loaded into the sample cylinder. The virial analysis of the data by Richter and McLinden [17] provides an independent estimate of $M$. We take the root-mean-square (RMS) average of the difference between the $M$ from the gravimetric preparation $M_{\text {grav }}$ and that determined from the virial analysis $M_{\text {virial }}$ to be the standard uncertainty in $M$ arising from sorption effects. This uncertainty is $0.0052 \mathrm{~g} \cdot \mathrm{mol}^{-1}$ (or $0.0114 \%$ to $0.0226 \%$ of $M$ or 0.00019 mole fraction), which is 2.8 to 32 times larger than the effect from the gravimetric preparation of the mixture.

The density uncertainty arising from the composition uncertainty (both mixture preparation and sorption effects) is thus

$$
u((x))=\times \frac{1}{M}\left[u\left(M_{\text {grav }}\right)^{2}+u(M)_{\text {atomic weights }}^{2}+u(M)_{\text {sorption }}^{2}\right]^{0.5} .
$$

\subsection{Uncertainty in dew point arising from data analysis}

The dew point is calculated by the intersection of two curves fitted to the data. Uncertainties result from (1) the assignment of a given data point to either the function fitted to the homogeneous vapor-phase data or the two-phase function and (2) the scatter in the data and the resulting uncertainty in the fitted coefficients. The assignment of a data point to either the "single-phase" or "two-phase" function was, in most cases, quite obvious. For points very near the dew point, however, the assignment can significantly affect the fit of the function(s) and, thus, the calculated dew point. We first fitted the data that were obviously in each of the regions and obtained the goodness-of-fit statistic, $R^{2}$; the "transition" points were then added one-by-one. If the $R^{2}$ statistic remained essentially constant, the point was retained; if, on the other hand, the $R^{2}$ changed significantly, that point was tested with the function for the other phase, or, in a few 
where the $u$ are the individual standard uncertainties, and the derivatives are calculated from the GERG equation. This value is tabulated in the Supplementary Data for each measured point. The relative combined expanded state-point uncertainty in density ranged from $0.035 \%$ at the highest densities measured to $0.21 \%$ at the lowest measured density $\rho=1.66 \mathrm{~kg} \cdot \mathrm{m}^{-3}$ (which was an absolute uncertainty of $0.0035 \mathrm{~kg} \cdot \mathrm{m}^{-3}$ ).

The combined expanded state-point uncertainty $(k=2)$ for the dew-point density also includes the variation of the dew-point density with temperature and composition and the uncertainty arising from the intersection of the single-phase and two-phase data: 


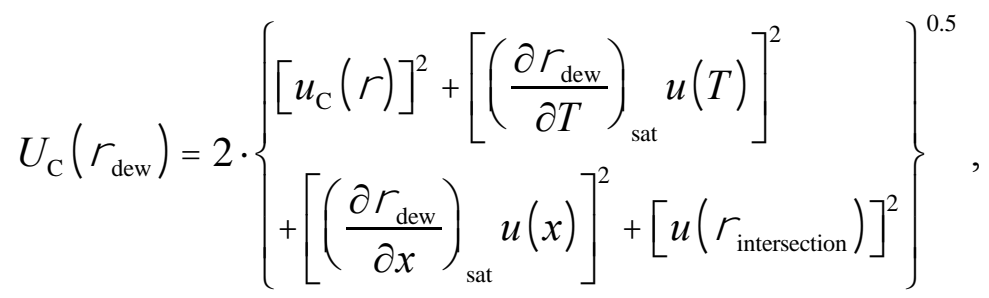

where $u_{\mathrm{C}}(\rho)$ is one-half of the expanded combined uncertainty in density (given by Eq 22), the derivatives of the dew-point density with respect to temperature and composition were numerically evaluated along the saturation (i.e., dew) line from the GERG equation, and the uncertainty in the intersection is the term discussed in section 4.4.

The combined expanded state-point uncertainty $(k=2)$ for the dew-point pressure is given by an expression analogous to Eq 23:

$$
U_{\mathrm{C}}\left(p_{\text {dew }}\right)=2 \cdot\left\{\begin{array}{l}
{[u(p)]^{2}+\left[\left(\frac{\partial p_{\text {dew }}}{\partial T}\right)_{\text {sat }} u(T)\right]^{2}} \\
+\left[\left(\frac{\partial p_{\text {dew }}}{\partial x}\right)_{\text {sat }} u(x)\right]^{2}+\left[u\left(p_{\text {intersection }}\right)\right]^{2}
\end{array}\right\}^{0.5} .
$$

When the dew-point pressure is computed from a virial fit of the vapor-phase data evaluated at the dew-point density, the combined expanded state-point uncertainty $(k=2)$ for the dew-point pressure is

$$
U_{\mathrm{C}}\left(p_{\text {dew }}\right)=2 \cdot\left\{\left[\left(\frac{\partial p}{\partial}\right)_{\text {dew point }} u_{\mathrm{C}}(\mathrm{dew})\right]^{2}+\left[u\left(p_{\text {virial }}\right)\right]^{2}\right\}^{0.5},
$$

where $u\left(p_{\text {virial }}\right)$ is the standard uncertainty in the virial fit, which we take as the RMS deviation given by Richter and McLinden [17]. The derivative of pressure with respect to density is evaluated in the vapor phase very close to the dew line. In this case, the uncertainty in the dewpoint pressure is primarily a function of the uncertainty in the dew-point density.

\section{Discussion and conclusions}

The $(p, \rho, T, x)$ behavior of three (methane + propane) mixtures was investigated with the NIST two-sinker densimeter over the temperature range of (248.15 to 293.15$) \mathrm{K}$; the measurements extended from low pressures into the two-phase region. These data were analyzed in several different ways. For the isothermal experiments, the measurements started at a low pressure, well 

percent above the dew-point pressure; the dew point was indicated by an abrupt change in slope. The "traditional" analysis of plotting (pressure versus density) as well as the novel method of plotting (adsorbed mass versus density) gave consistent results. The uncertainties for the adsorbed mass analysis were lower in most cases. A further, significant advantage of the (adsorbed mass versus density) analysis was that the dew point was quite distinct, even when the measurements extended only slightly into the two-phase region.

A similar analysis plotting adsorbed mass versus pressure resulted in larger scatter and uncertainties in the two-phase data because of increased uncertainty in the pressure measurement. Thus, we recommend that the dew-point pressure be calculated from extrapolating a virial fit of the single-phase vapor ( $p$ vs. $\rho$ ) data to the dew-point density. This effect was largely a consequence of the configuration of the pressure measuring system in our instrument, and it could be avoided in an instrument optimized for dew-point measurements by heating the pressure line and pressure transducer such that condensation would not occur in the pressure system.

An isochoric experiment, in which a fixed quantity of sample was slowly cooled from slightly above to slightly below the dew-point temperature, was also carried out. This experiment yielded results consistent with the isothermal experiments. The uncertainties arose primarily because of the continuously changing temperature. In contrast with the "traditional" isochoric experiment, which is conducted in a simple closed vessel, we continuously measured the density in our experiment and, thus, also obtained the dew-point density. The isochoric experiment required (18 to 48 ) hours to carry out, or about the same total time as a complete isothermal series, but it yielded only the dew-point data. In contrast, the isothermal experiment also yielded single-phase vapor $(p, \rho, T, x)$ data. Thus, the isothermal experiment is preferred.

We carried out a detailed uncertainty analysis for our measurements, including a consideration of the uncertainties arising from sorption effects on the mixture composition. These effects are not typically considered in literature sources of dew-point data, and this may be responsible for a portion of the large scatter observed in the literature data.

This work has demonstrated that the analysis of sorption/condensation effects is a useful technique for the detection of dew points. It provides a quantitative measure of the adsorbed/condensed mass on the sinker surfaces, not just a change in slope, as is typical with many traditional dew-point measurement techniques. The uncertainties in the dew points determined with this technique were often, but not always, lower than traditional techniques; the 
cases with larger uncertainties corresponded to isotherms that extended only slightly into the two-phase region. With more experience, we will be able to obtain consistently the lower uncertainties. We considered only binary systems in this work, which are the simplest. May et al. [4], for example, measured both binary and ternary systems and found that the dew point was less distinct for the ternary. We will be investigating multi-component mixtures with our new method in the near future.

Finally, we note that our instrument was not optimal for detecting adsorption onto the sinkers; in particular, our sinkers had approximately equal surface areas and a similar surface finishdetails specifically intended to "cancel out" sorption effects, as discussed by Kleinrahm and Wagner [13] in the description of their original two-sinker densimeter. This suggests that a densimeter with two sinkers of the same mass and same material (and thus the same volume), but having very different surface areas and/or surface finishes, could better detect sorption phenomena. Such a modification is the topic of a companion paper [18].

\section{Acknowledgements}

This work was funded by the National Institute of Standards and Technology (NIST). We thank the Deutsche Forschungsgemeinschaft (DFG) for supporting the stay of Dr. M. Richter at NIST under Grant No. RI 2482/1-1 and for funding our ongoing research within the Emmy Noether Programme under Grant No. RI 2482/2-1. We thank our NIST colleagues Dr. Eric Lemmon for providing his database of literature data and Dr. Thomas Bruno for providing the analysis of our experimental samples. We thank Dr. Reiner Kleinrahm of Ruhr-Universität Bochum for his careful reading of the manuscript and many helpful suggestions. 


\section{References}

1. Blanco, S. T.; Velasco, I.; Rauzy, E.; Otin, S., Water dew points of binary nitrogen + water and propane + water mixtures. Measurement and correlation. Fluid Phase Equilib. 1999, $161,107-117$.

2. Louli, V.; Pappa, G.; Boukouvalas, C.; Skouras, S.; Solbraa, E.; Christensen, K. O.; Voutsas, E., Measurement and prediction of dew point curves of natural gas mixtures. Fluid Phase Equilib. 2012, 334, 1-9.

3. Zarrabian, S. Apparatus and method for measuring the dew point of gases using spectral recognition of the condensate. U.S. Patent 7,581,877B1, Sep. 01, 2009.

4. May, E. F.; Miller, R. C.; Shan, Z., Densities and dew points of vapor mixtures of methane + propane and methane + propane + hexane using a dual-sinker densimeter. J. Chem. Eng. Data 2001, 46, 1160-1166.

5. Zhou, J.; Patil, P.; Ejaz, S.; Atilhan, M.; Holste, J. C.; Hall, K. R., $\left(p, V_{\mathrm{m}}, T\right)$ and phase equilibrium measurements for a natural gas-like mixture using an automated isochoric apparatus. J. Chem. Thermodyn. 2006, 38, 1489-1494.

6. Atilhan, M.; Aparicio, S.; Ejaz, S.; Christancho, D.; Mantilla, I.; Hall, K. R., P $\rho T$ Behavior of three lean synthetic natural gas mixtures using a magnetic suspension densimeter and an isochoric apparatus from (250 to 450$) \mathrm{K}$ with pressures up to $150 \mathrm{MPa}$ : Part II. J. Chem. Eng. Data 2011, 56, 3766-3774.

7. Shapiro, A. P.; Dean, A. J., Quartz crystal microbalance dewpoint sensor for natural gas. Proc. SPIE 1999, 3856, 148-159.

8. Kwon, S.-Y.; Kim, J.-C.; Choi, B.-I., Accurate dew-point measurement over a wider temperature range using a quartz crystal microbalance dew-point sensor. Meas. Sci. Technol. 2008, 19, 1-7.

9. Rogers, W. J.; Holste, J. C.; Eubank, P. T.; Hall, K. R., Microwave apparatus for phase transition studies of corrosive fluids to $1.7 \mathrm{kbar}$ and 588 K. Rev. Sci. Instrum. 1985, 56, 1907-1912.

10. May, E. F.; Edwards, T. J.; Mann, A. G.; Edwards, C., An improved microwave apparatus for phase behavior measurements in lean gas condensate fluids. Fluid Phase Equilib. 2004, $215,245-252$.

11. Colgate, S. O.; Sivaraman, A.; Dejsupa, C.; McGill, K. Sonic speed measurement in natutal gas mixtures at $298 \mathrm{~K}$ to $245 \mathrm{~K}$ with pressures to $0.52 \mathrm{MPa}$. Proceedings of the International Gas Union Research Conference, Tokyo, Japan, IGRC: Tokyo, Japan, 1989.

12. Sivaraman, A. Hydrocarbon dewpoint measurement device and method. Patent Application No. US 2007/0249058A1, Oct. 25, 2007.

13. Kleinrahm, R.; Wagner, W., Measurement and correlation of the equilibrium liquid and vapour densities and the vapour pressure along the coexistence curve of methane. J. Chem. Thermodyn. 1986, 18, 739-760.

14. Wagner, W.; Kleinrahm, R., Densimeters for very accurate density measurements of fluids over large ranges of temperature, pressure, and density. Metrologia 2004, 41, S24-S39.

15. Kunz, O.; Wagner, W., The GERG-2008 wide-range equation of state for natural gases and other mixtures: An expansion of GERG-2004. J. Chem. Eng. Data 2012, 57, 3032-3091.

16. McLinden, M. O.; Lösch-Will, C., Apparatus for wide-ranging, high-accuracy fluid $(p-\rho-T)$ 

507-530.

17. Richter, M.; McLinden, M. O., Vapor-phase $(p, \rho, T, x)$ behavior and virial coefficients for the (methane + propane) system. J. Chem. Eng. Data 2014, 59, 4151-4164.

18. Richter, M.; McLinden, M. O., Application of a two-sinker densimeter for the measurement of phase equilibria: Quantitative investigation of surface phenomena. $J$. Chem. Thermodyn. 2016, (manuscript in preparation).

19. McLinden, M. O.; Kleinrahm, R.; Wagner, W., Force transmission errors in magnetic suspension densimeters. Int. J. Thermophysics 2007, 28, 429-448.

20 Landolt-Börnstein, Numerical Data and Functional Relationships in Science and Technology, New Series, II/16, Diamagnetic Susceptibility, Springer-Verlag, Heidelberg, 1986.

21. Harris, G. L.; Torres, J. A. Selected laboratory and measurement practices and procedures, to support basic mass calibrations; NISTIR 6969; National Institute of Standards and Technology: 2003.

22. Kunz, O.; Klimeck, R.; Wagner, W.; Jaeschke, M., The GERG-2004 Wide-Range Equation of State for Natural Gases and Other Mixtures, GERG TM15. Fortschritt-Berichte VDI: 2007; Vol. 6, No. 557.

23. Lemmon, E.W. 2015. personal communication, National Institute of Standards and Technology, Boulder, Colorado, USA.

24. Kalra, H.; Robinson, D. B., An apparatus for the simultaneous measurement of equilibrium phase. Cryogenics 1975, 15, 409-412.

25. Powers, J. E.; Manker, E. A.; Mather, A. E.; Yesavage, V. F. In Vapor-liquid equilibrium data for the methane-propane system, AIChE 65th National Meeting, May 4-7, 1969.

26. Cutler, A. J. B.; Morrison, J. A., Excess Thermodynamic functions for liquid mixtures of methane + propane. Trans. Faraday Soc. 1965, 61, 429-442.

27. Roof, J. G.; Baron, J. D., Critical loci of binary mixtures of propane with methane, carbon dioxide, and nitrogen. J. Chem. Eng. Data 1967, 12, 292-293.

28. Stoeckli, H. F.; Staveley, L. A. K., Low Temperature Thermodynamics. The Excess Gibbs Function and the Volumes of Mixing for the System Methane + Propane at 90.68K. Helv. Chim. Acta 1970, 53, 1961-1964.

29. May, E. F.; Guo, J. Y.; Oakley, J. H.; Hughes, T. J.; Graham, B. F.; Marsh, K. N.; Huang, S. H., Reference quality vapor-liquid equilibrium data for the binary systems methane + ethane, + propane, + butane, and + 2- methylpropane, at temperatures from (203 to 273) K and pressures to $9 \mathrm{MPa}$. J. Chem. Engr. Data 2015, 60, 3606-3620.

30. Webster, L. A.; Kidnay, A. J., Vapor-liquid equilibria for the methane-propane-carbon dioxide systems at $230 \mathrm{~K}$ and 270 K. J. Chem. Eng. Data 2001, 46, 759-764.

31. Price, R. A.; Kobayashi, R., Low temperature vapor-liquid equilibrium in light hydrocarbon mixtures: Methane-ethane-propane System. J. Chem. Eng. Data 1959, 4, 4052.

32. Sage, B. H.; Lacey, W. N.; Schaafsma, J. G., Phase equilibria in hydrocarbon systems, II. Methane-propane system. Ind. Eng. Chem. 1934, 26, 214-217. 
33. Reamer, H. H.; Sage, B. H.; Lacey, W. N., Phase equilibria in hydrocarbon systems, volumetric and phase behavior of the methane-propane system. Ind. Eng. Chem. 1950, 42, 534-539.

34. McLinden, M. O.; Splett, J. D., A liquid density standard over wide ranges of temperature and pressure based on toluene. J. Res. Natl. Inst. Stand. Technol. 2008, 113, 29-67.

35. Wieser, M. E.; Holden, N.; Coplen, T. B.; Böhlke, J. K.; Berglund, M.; Brand, W. A.; De Bievre, P.; Gröning, M.; Loss, R. D.; Meija, J.; Hirata, T.; Prohaska, T.; Schoenberg, R.; O'Connor, G.; Walczyk, T.; Yoneda, S.; Zhu, X., Atomic weights of the elements 2011 (IUPAC Technical Report). Pure Appl. Chem. 2013, 85, 1047-1078.

36. Boggs, P. T.; Byrd, R. H.; Donaldson, J. R.; Schnabel, R. B., Algorithm 676 - ODRPACK: Software for weighted orthogonal distance regression. ACM Trans. Math. Software 1989, 15, 348-364.

37. Wiese, H. C.; Jacobs, J.; Sage, B. H., Phase equilibria in the hydrocarbon systems. Phase behavior in the methane-propane-n-butane System. J. Chem. Eng. Data 1970, 15, 82-91.

38. Price, A.R. Low temperature vapor-liquid equilibrium in light hydrocarbon mixtures: methane-ethane-propane system, Rice University, PhD Dissertation, 1957.

39. Akers, W. W.; Kelley, R. E.; Lipscomb, T. G., Carbon dioxide-propane system, lowtemperature phase equilibria. Ind. Eng. Chem. 1954, 46, 2535.

40. Calado, J. C. G.; Garcia, G. A.; Staveley, L. A. K., Thermodynamics of the liquid system methane + propane. J. Chem. Soc., Faraday Trans. 1 1974, 70, 1445-1451.

41. Cheung, H.; Wang, D. I., Solubility of volatile gases in hydrocarbon solvents at cryogenic temperatures. Ind. Eng. Chem. Fundam. 1964, 3, 355-361.

42. Joffe, J., Vapor-liquid equilibria by the pseudocritical method. Ind. Eng. Chem. Fundam. 1976, 15, 298-304.

43. Poon, D. P. L.; Lu, B. C.-Y., Phase equilibria for systems containing nitrogen, methane and propane. Adv. Cryo. Eng. 1974, 19, 292-299.

44. Skripka, V. G.; Nikitina, I. E.; Zhdanovich, L. A.; Sirotin, A. G.; Benyaminovich, O. A., Liquid-vapor phase equilibrium at low temperatures in binary systems, components produced from natural gas. Gazov Promst. 1970, 15 (12), 35-36.

45. Wichterle, I.; Kobayashi, R., Vapor-Liquid Equilibrium of Methane-Propane System at Low Temperatures and High Pressures. J. Chem. Eng. Data 1972, 17, 4-9.

46. Wilson, G. M., Vapor-liquid equilibria of nitrogen, methane, ethane and propane binary mixtures at LNG temperatures from total pressure measurements. Adv. Cryo. Eng. 1975, 20, 164-171.

47. Kandil, M. E.; Marsh, K. N.; Goodwin, A. R. H., A re-entrant resonator for the measurement of phase boundaries: dew points for $\left(0.4026 \mathrm{CH}_{4}+0.5974 \mathrm{C}_{3} \mathrm{H}_{8}\right)$. J. Chem. Thermodynamics 2005, 37, 684-691. 
Table 1. Sample information.

\begin{tabular}{lccccc}
\hline $\begin{array}{l}\text { Chemical } \\
\text { Name }\end{array}$ & Source & $\begin{array}{c}\text { Initial Purity/ } \\
\text { mole fraction }\end{array}$ & $\begin{array}{c}\text { Purification } \\
\text { Method }\end{array}$ & $\begin{array}{c}\text { Final Purity/ } \\
\text { mole fraction }\end{array}$ & $\begin{array}{c}\text { Analysis } \\
\text { Method }\end{array}$ \\
\hline methane & Matheson & 0.99999 & none & 0.99999 & GC/MS \\
propane & Scott & 0.99999 & none & 0.99999 & GC/MS \\
\hline
\end{tabular}

${ }^{\mathrm{a}}$ Gas chromatography/mass spectrometry

Table 2. Gravimetric compositions (mole fraction) and average molar mass of the studied mixtures.

\begin{tabular}{l|ccc}
\hline \multirow{2}{*}{ Component } & \multicolumn{3}{|c}{ Mole fraction mixture } \\
\cline { 2 - 4 } & $(75 / 25)$ & $(50 / 50)$ & $(27 / 73)$ \\
\hline Methane & 0.74977 & 0.50688 & 0.26579 \\
Propane & 0.25023 & 0.49312 & 0.73421 \\
\hline \multirow{2}{M/g}{$\cdot \mathrm{mol}^{-1}$} & 23.0623 & 29.8761 & 36.6393 \\
\hline
\end{tabular}


Table 3. Summary of dew-point densities and pressures $\rho_{\text {dew }}$ and $p_{\text {dew }}$ from the isothermal experiments evaluated by the "traditional" intersection of pressure versus density, relative combined expanded uncertainties $(k=2)$; and relative deviations to the GERG model of Kunz and Wagner [15] $\Delta_{\rho \text {,dew }}$ and $\Delta_{p \text {,dew }}$; the standard uncertainty in temperature was $3 \mathrm{mK}$.

\begin{tabular}{|c|cccccc|}
\hline & \multicolumn{7}{|c|}{$p$ versus $\rho$} \\
\hline$T$ & $\begin{array}{c}\rho_{\text {dew }} \\
/ \mathrm{K}\end{array} / \mathrm{kg} \cdot \mathrm{m}^{-3}$ & $\begin{array}{c}p_{\text {dew }} / \mathrm{MPa} \\
U_{\mathrm{C}}\left(\rho_{\text {dew }}\right)\end{array}$ & $\begin{array}{c}U_{\mathrm{C}}\left(p_{\text {dew }}\right) \\
/ \%\end{array}$ & $\begin{array}{c}\Delta_{\rho, \text { dew }} \\
/ \%\end{array}$ & $\begin{array}{c}\Delta_{\mathrm{p}, \text { dew }} \\
/ \%\end{array}$ \\
\hline$x_{\text {methane }}=0.26579 ; u(x)=0.00020$ \\
\hline 248.152 & 5.309 & 0.2821 & 0.22 & 0.34 & -0.09 & 0.02 \\
273.149 & 12.027 & 0.6685 & 0.10 & 0.24 & -1.23 & -0.48 \\
273.149 & 12.026 & 0.6684 & 0.16 & 0.68 & -1.24 & -0.49 \\
293.146 & 21.457 & 1.2049 & 0.09 & 0.31 & -2.41 & -0.99 \\
\hline$x_{\text {methane }}=0.50688 ; u(x)=0.00019$ & & & \\
\hline 248.151 & 6.627 & 0.4324 & 0.80 & 1.52 & -0.34 & -0.03 \\
273.148 & 15.266 & 1.0410 & 0.11 & 0.12 & -2.88 & -2.06 \\
273.149 & 15.322 & 1.0445 & 0.14 & 0.24 & -2.52 & -1.73 \\
273.149 & 15.226 & 1.0387 & 0.16 & 0.34 & -3.14 & -2.28 \\
293.147 & 28.360 & 1.9440 & 0.10 & 0.12 & -5.36 & -3.69 \\
\hline$x_{\text {methane }}=0.74977 ; u(x)=0.00019$ & & & \\
\hline 248.161 & 10.590 & 0.8861 & 0.49 & 0.50 & -2.61 & -2.30 \\
273.152 & 27.730 & 2.3666 & 0.42 & 0.41 & -4.13 & -3.40 \\
\hline
\end{tabular}


Table 4. Summary of dew-point densities and pressures $\rho_{\text {dew }}$ and $p_{\text {dew }}$ from the isothermal experiments evaluated by the intersection of the adsorbed mass $\Delta m_{\text {sorption }}$ versus ( $p$ or $\rho)$; relative deviations to the GERG model of Kunz and Wagner [15] $\Delta_{\rho \text {,dew }}$ and $\Delta_{p \text {,dew }}$; and relative combined expanded uncertainties $(k=2), U_{\mathrm{C}}\left(\rho_{\text {dew }}\right)$ and $U_{\mathrm{C}}\left(p_{\text {dew }}\right)$; the standard uncertainty in temperature was $3 \mathrm{mK}$.

\begin{tabular}{|c|c|c|c|c|c|c|c|c|c|}
\hline \multirow[b]{2}{*}{$\begin{array}{l}T \\
\mathrm{~K} \\
\end{array}$} & \multicolumn{3}{|c|}{$\Delta m_{\text {sorption }}$ versus $p$} & \multicolumn{6}{|c|}{$\Delta m_{\text {sorption }}$ versus $\rho$} \\
\hline & $\begin{array}{c}p_{\text {dew }} \\
/ \mathrm{MPa} \\
\end{array}$ & $\begin{array}{c}U_{\mathrm{C}}\left(p_{\text {dew }}\right) \\
1 \%\end{array}$ & $\begin{array}{c}\Delta_{p, \text { dew }} \\
1 \% \\
\end{array}$ & $\begin{array}{c}\rho_{\text {dew }} \\
/ \mathrm{kg} \cdot \mathrm{m}^{-3} \\
\end{array}$ & $\begin{array}{l}p_{\text {dew }} * \\
/ \mathrm{MPa} \\
\end{array}$ & $\begin{array}{c}U_{\mathrm{C}}\left(\rho_{\text {dew }}\right) \\
1 \%\end{array}$ & $\begin{array}{c}U_{\mathrm{C}}\left(p_{\text {dew }}\right) \\
1 \%\end{array}$ & $\begin{array}{c}\Delta_{\rho, \text { dew }} \\
1 \%\end{array}$ & $\begin{array}{c}\Delta_{\mathrm{p}, \text { dew }} \\
1 \%\end{array}$ \\
\hline \multicolumn{10}{|c|}{$x_{\text {methane }}=0.26579 ; u(x)=0.00020$} \\
\hline 248.152 & 0.2799 & 2.40 & -0.76 & 5.273 & 0.2803 & 0.83 & 0.83 & -0.95 & -0.61 \\
\hline 273.149 & 0.6649 & 0.62 & -1.01 & 12.008 & 0.6676 & 0.13 & 0.14 & -1.39 & -0.61 \\
\hline 273.149 & 0.6638 & 0.65 & -1.18 & 12.003 & 0.6674 & 0.11 & 0.12 & -1.43 & -0.64 \\
\hline 293.146 & 1.2046 & 0.80 & -1.01 & 21.393 & 1.1974 & 0.76 & 0.76 & -2.70 & -1.60 \\
\hline \multicolumn{10}{|c|}{$x_{\text {methane }}=0.50688 ; u(x)=0.00019$} \\
\hline 248.151 & 0.4236 & 2.06 & -2.06 & 6.552 & 0.4277 & 0.97 & 0.97 & -1.46 & -1.11 \\
\hline 273.148 & 1.0553 & 0.72 & -0.71 & 15.375 & 1.0477 & 0.11 & 0.12 & -2.18 & -1.43 \\
\hline 273.149 & 1.0369 & 0.82 & -2.45 & 15.239 & 1.0395 & 0.38 & 0.38 & -3.05 & -2.20 \\
\hline 273.149 & 1.0584 & 0.46 & -0.42 & 15.425 & 1.0476 & 0.13 & 0.14 & -1.87 & -1.44 \\
\hline 293.147 & 1.9504 & 0.21 & -3.32 & 28.420 & 1.9275 & 0.08 & 0.09 & -5.16 & -4.50 \\
\hline \multicolumn{10}{|c|}{$x_{\text {methane }}=0.74977 ; u(x)=0.00019$} \\
\hline 248.161 & 0.9132 & 0.29 & 0.69 & 10.873 & 0.9080 & 0.19 & 0.20 & 0.00 & 0.12 \\
\hline 273.152 & 2.4320 & 0.29 & -0.73 & 28.441 & 2.4186 & 0.25 & 0.25 & -1.67 & -1.27 \\
\hline
\end{tabular}


Table 5. Summary of dew-point temperatures, pressures and densities $T_{\text {dew }}, p_{\text {dew }}$ and $\rho_{\text {dew }}$, from the isochoric experiments on the methane/propane mixture with a composition of ( 0.26579 methane +0.73421 propane $)$; relative combined expanded uncertainties $U_{\mathrm{C}}\left(p_{\text {dew }}\right)$ and $U_{\mathrm{C}}\left(\rho_{\text {dew }}\right)$; and relative deviations to the GERG model of Kunz and Wagner [15] $\Delta_{\rho \text {,dew }}$ and $\Delta_{p \text {,dew; }}$, the dew points were evaluated from the "traditional" intersection of temperature $T$ versus pressure $p$ and by the intersection of pressure versus density $\rho$; the standard uncertainty in the composition was $0.00020 \mathrm{~mol}$ frac.

\begin{tabular}{|c|c|c|c|c|c|c|c|c|c|c|}
\hline \multicolumn{5}{|c|}{$T$ versus $p$} & \multicolumn{6}{|c|}{$p$ versus $\rho$} \\
\hline$\underset{\mathrm{K}}{T_{\mathrm{Du \square}}}$ & $\begin{array}{l}p_{\text {dew }} \\
\text { /MPa }\end{array}$ & $\begin{array}{c}U_{\mathrm{C}}\left(T_{\text {dew }}\right) \\
/ \mathrm{K}\end{array}$ & $\begin{array}{c}U_{\mathrm{C}}\left(p_{\text {dew }}\right) \\
1 \%\end{array}$ & $\begin{array}{c}\Delta_{p \text {,dew }} \\
1 \%\end{array}$ & $\begin{array}{l}p_{\text {dew }} \\
/ \mathrm{MPa}\end{array}$ & $\begin{array}{c}\rho_{\mathrm{dew}} \\
/ \mathrm{kg} \cdot \mathrm{m}^{-3}\end{array}$ & $\begin{array}{c}U_{\mathrm{C}}\left(\rho_{\text {dew }}\right) \\
1 \%\end{array}$ & $\begin{array}{c}U_{\mathrm{C}}\left(p_{\text {dew }}\right) \\
1 \%\end{array}$ & $\begin{array}{c}\Delta_{\mathrm{p}, \text { dew }} \\
1 \%\end{array}$ & $\begin{array}{c}\Delta_{\rho, \mathrm{dew}} \\
1 \%\end{array}$ \\
\hline 273.409 & 0.6722 & 0.100 & 0.33 & -0.74 & 0.6720 & 12.086 & 0.31 & 0.32 & -1.54 & -0.77 \\
\hline 293.815 & 1.2225 & 0.103 & 0.29 & -1.41 & 1.2224 & 21.750 & 0.30 & 0.29 & -2.95 & -1.41 \\
\hline
\end{tabular}



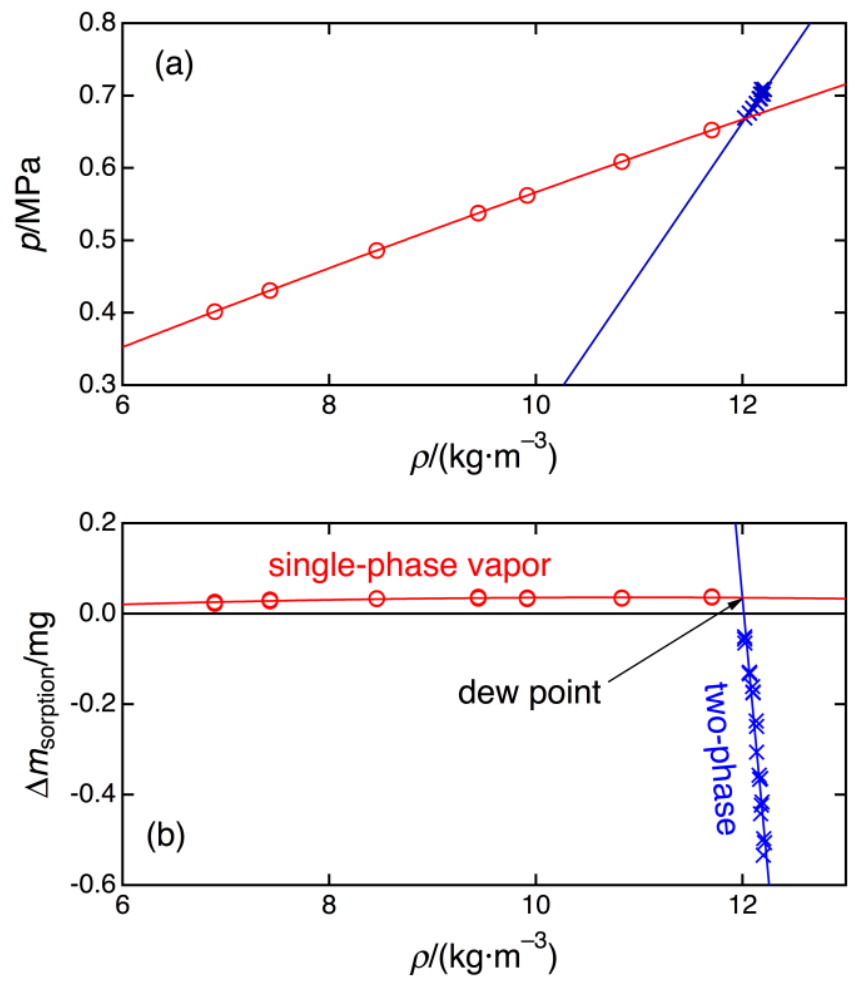

Figure 1. Results for the isotherm at $T=273.149 \mathrm{~K}$, with a composition of $(0.26579$ methane + 0.73421 propane); (a) the "traditional" plot of pressure versus density; (b) adsorbed mass versus density; $\circ$, single-phase data; $\times$, two-phase data; the lines are fitted to the data in each region. 

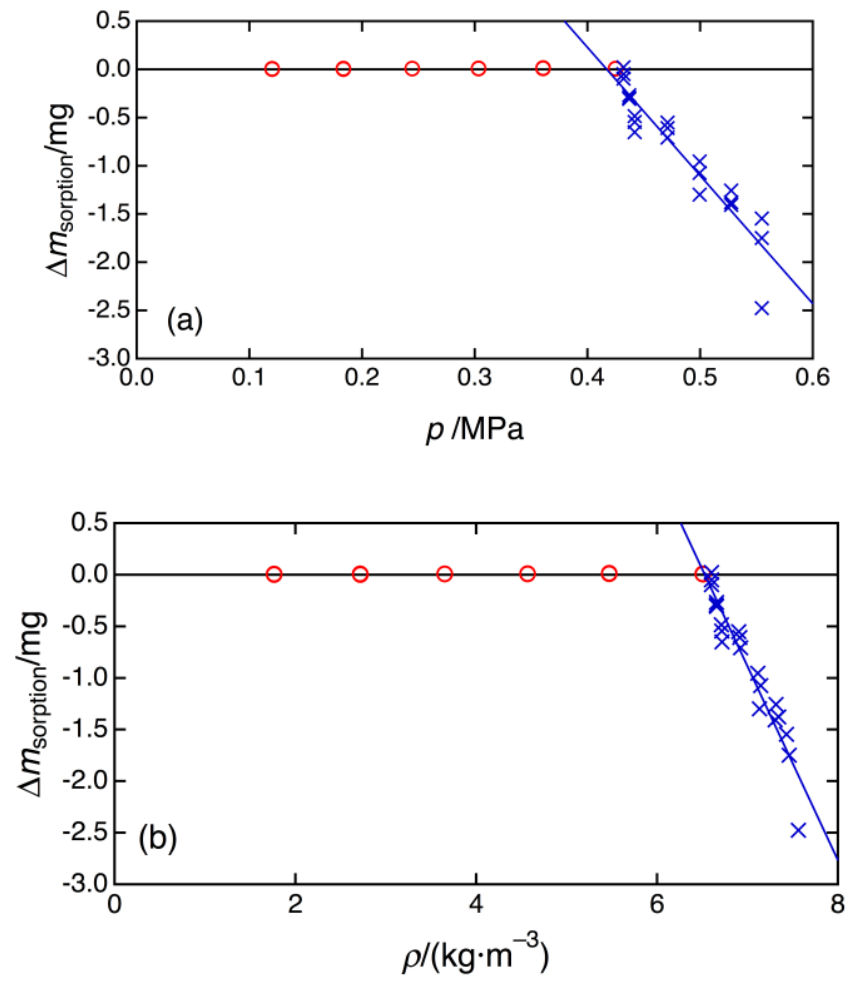

Figure 2. Results for the isotherm at $T=248.151 \mathrm{~K}$, with a composition of ( 0.50688 methane + 0.49312 propane), with the adsorbed mass plotted versus pressure (a) and versus density (b); $\odot$, single-phase data; $\times$, two-phase data; the lines are fitted to the data in each region. 

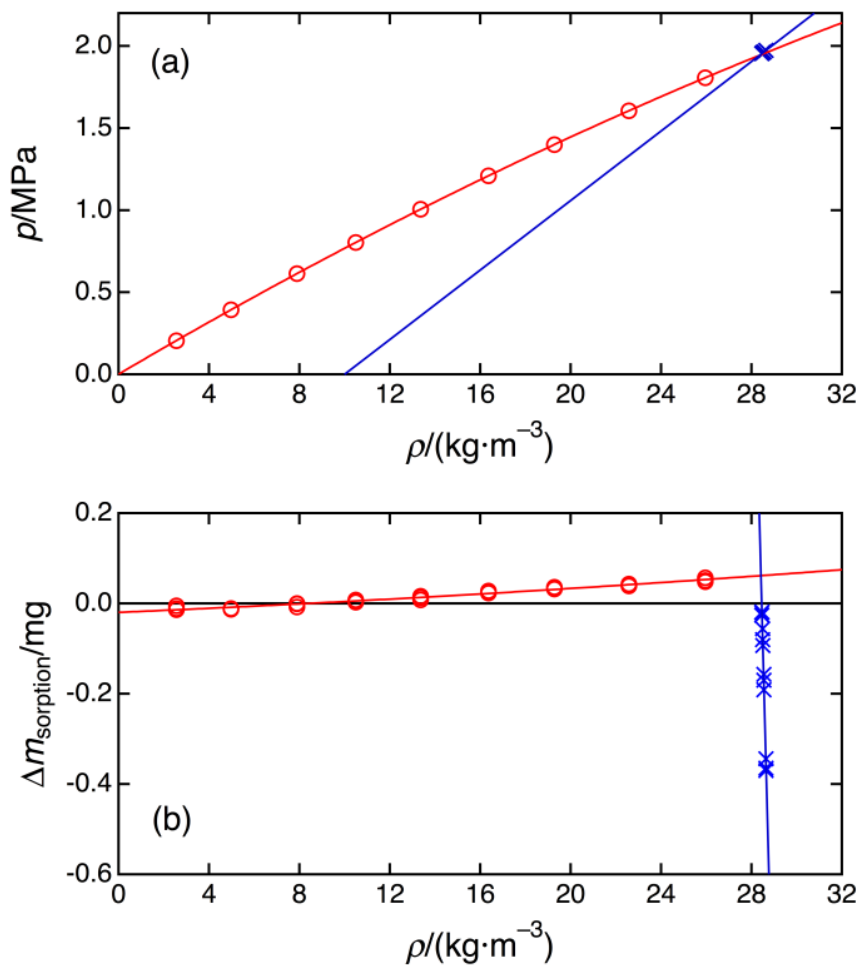

Figure 3. Results for the isotherm at $T=293.147 \mathrm{~K}$ for the $(0.50688$ methane +0.49312 propane $)$ mixture; (a) the dew point is difficult to detect in the "traditional" plot of pressure versus density; (b) the dew point is easily identified in the plot of adsorbed mass versus density; $\circ$, single-phase data; $\times$, two-phase data; the lines are fitted to the data in each region. 
Figure 4. Relative deviations of experimental dew-point densities $\rho_{\text {dew,exp }}$ at $T=(248.15,273.15$ and 293.15) K from those calculated with the GERG-2008 equation of state of Kunz and Wagner [15]; $\odot$, isotherms measured on the $(0.26579$ methane +0.73421 propane $)$ mixture; $\times$, isotherms measured on the $(0.50688$ methane +0.49312 propane) mixture; $\Delta$, isotherms measured on the $(0.74977$ methane +0.25023 propane) mixture; $₫$ isochoric measurements on the $(0.26579$ methane +0.73421 propane) mixture. The error bars show the relative combined expanded uncertainty $(k=2)$ in the measured dew-point densities. 

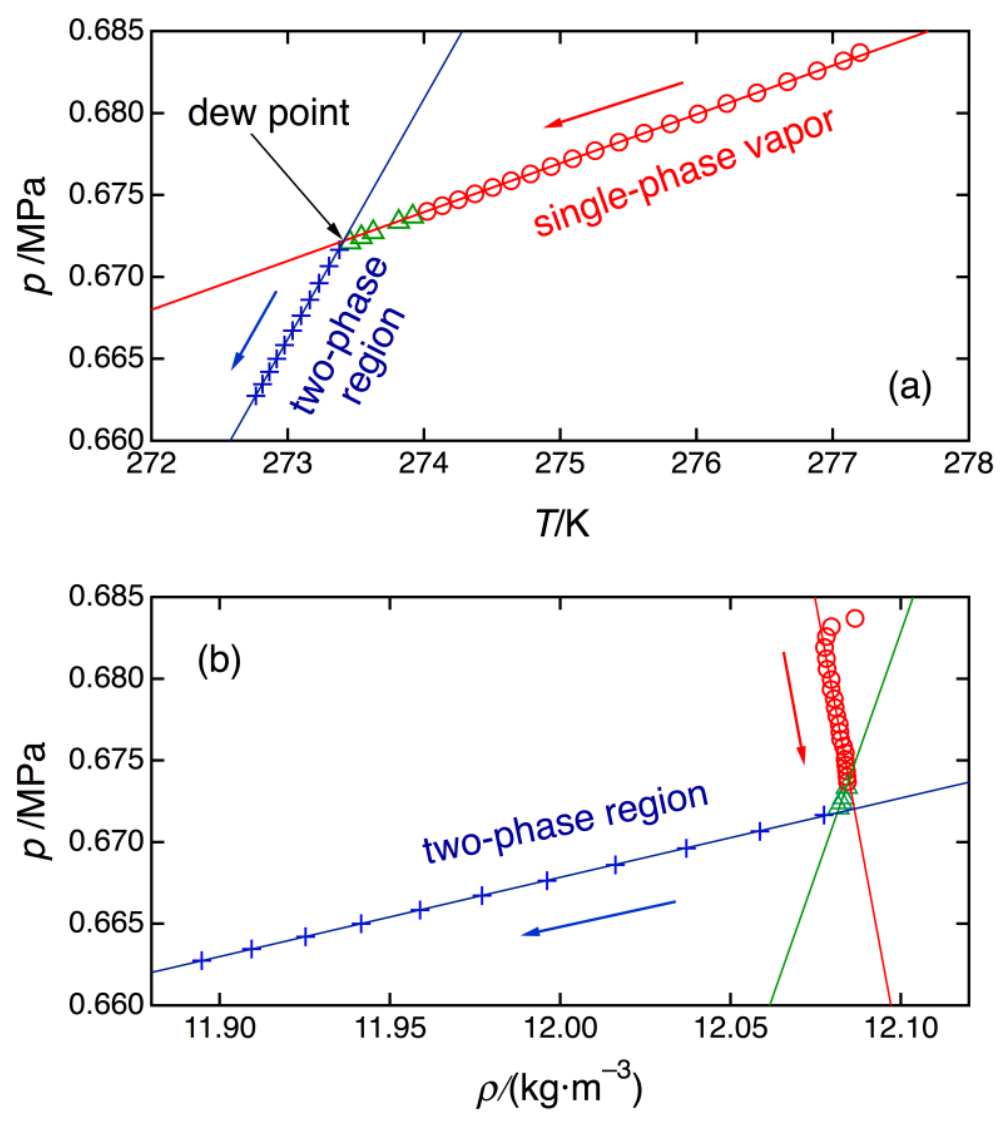

Figure 5. Results for the isochoric measurements on the ( 0.26579 methane +0.73421 propane) mixture; (a) a "traditional" plot of pressure versus temperature; (b) a plot of pressure versus density; $\circ$, single-phase data; $\triangle$, "precondensation" region; +, two-phase data; the lines are fitted to the data in each region. 


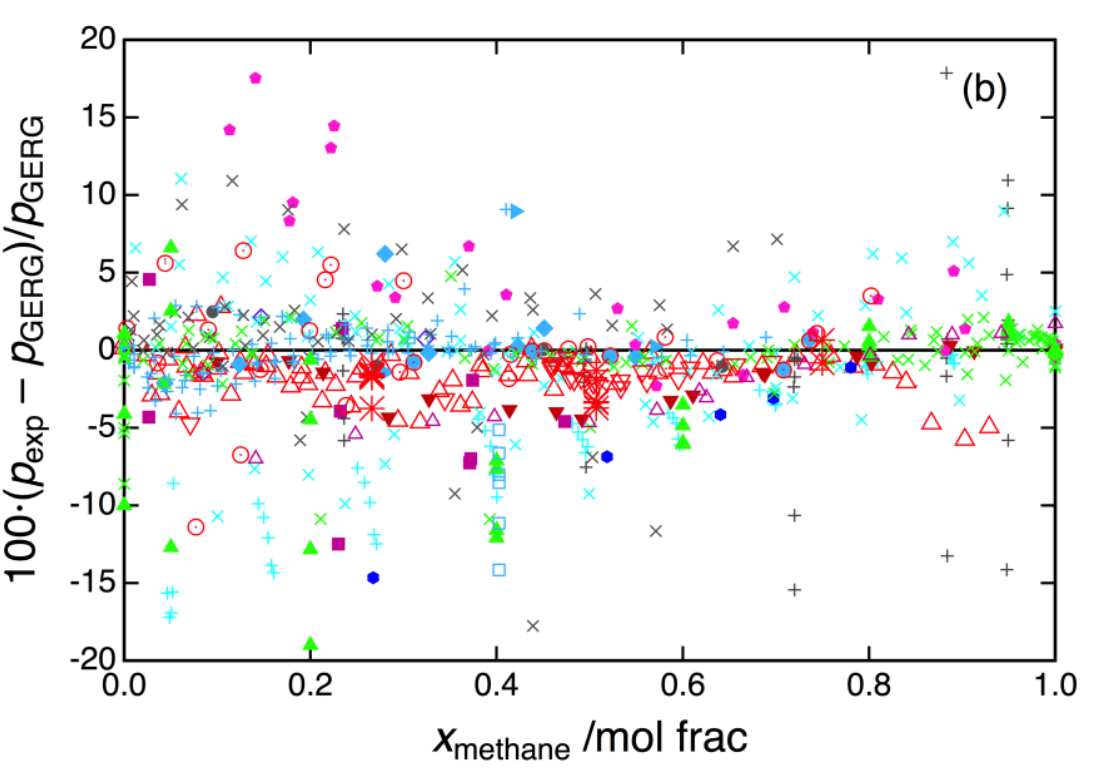

Figure 6. Relative deviations of experimental saturation pressures $p_{\exp }$ for (methane + propane) mixtures from saturation pressures $p_{\text {GERG }}$ calculated with the GERG-2008 equation of state of Kunz and Wagner[15]; (a) plotted as a function of temperature; (b) plotted as a function of composition; $₫$, present results ("sorption analysis"); other symbols show literature data as indicated in the legend. 


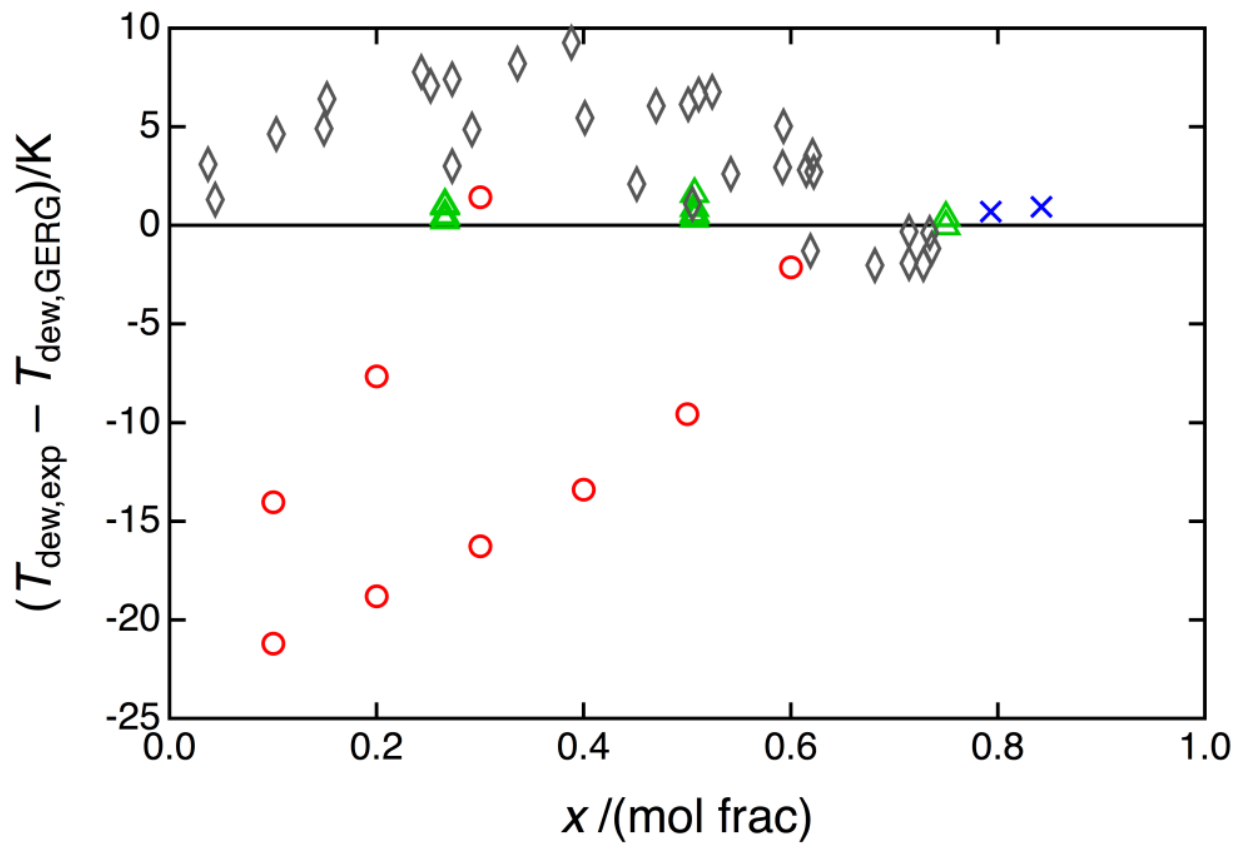

Figure 7. Deviations of experimental dew-point temperatures, $T_{\text {dew,exp }}$, from $T_{\text {dew }}$ calculated as a function of experimental dew-point density, $T_{\text {dew,GERG }}\left(x, \rho_{\text {dew,exp }}\right)$, with the GERG2008 equation of Kunz and Wagner [15]; $\triangle$, present data ("sorption analysis"); $\diamond$, Sage et al. [32]; O, Reamer et al. [33]; X, May et al. [4]. 
references from Fig 6 (note: these are so that EndNote includes the sources plotted on the figure in the reference list)

Wiese et al. [37]

Yesavage

Webster and Kidnay [30]

Kalra and Robinson [24]

Powers et al. [25]

Price [38]

Cutler [26]

Roof and Baron [27]

Akers et al. [39]

Calado et al. [40]

Cheung and Wang [41]

Joffe [42]

Poon and $\mathrm{Lu}[43]$

Price and Kobayashi [31]

Skripka et al. [44]

Stoeckli and Staveley [28]

Wichterle and Kobayashi [45]

Wilson [46]

Kandil et al. [47]

[1]S.T. Blanco, I. Velasco, E. Rauzy, O. S., Fluid Phase Equilib. 161 (1999) 107-117.

[2]V. Louli, G. Pappa, C. Boukouvalas, S. Skouras, E. Solbraa, K.O. Christensen, E. Voutsas, Fluid Phase Equilib. 334 (2012) 1-9.

[3]S. Zarrabian, Apparatus and method for measuring the dew point of gases using spectral recognition of the condensate., U.S., 2009.

[4]E.F. May, R.C. Miller, Z. Shan, J. Chem. Eng. Data 46 (2001) 1160-1166.

[5]J. Zhou, P. Patil, S. Ejaz, M. Atilhan, J.C. Holste, K.R. Hall, J. Chem. Thermodyn. 38 (2006) 1489-1494.

[6]M. Atilhan, S. Aparicio, S. Ejaz, D. Christancho, I. Mantilla, K.R. Hall, J. Chem. Eng. Data 56 (2011) 3766-3774.

[7]A.P. Shapiro, A.J. Dean, Proc. SPIE 3856 (1999) 148-159.

[8]S.-Y. Kwon, J.-C. Kim, B.-I. Choi, Meas. Sci. Technol. 19 (2008) 1-7.

[9]W.J. Rogers, J.C. Holste, P.T. Eubank, K.R. Hall, Rev. Sci. Instrum. 56 (1985) 1907-1912.

[10]E.F. May, T.J. Edwards, A.G. Mann, C. Edwards, Fluid Phase Equilib. 215 (2004) 245-252.

[11]S.O. Colgate, A. Sivaraman, C. Dejsupa, K. McGill, Sonic speed measurement in natutal gas mixtures at $298 \mathrm{~K}$ to $245 \mathrm{~K}$ with pressures to $0.52 \mathrm{MPa}$., Proceedings of the International Gas Union Research Conference, IGRC, Tokyo, Japan, 1989.

[12]A. Sivaraman, Hydrocarbon dewpoint measurement device and method, 2007.

[13]R. Kleinrahm, W. Wagner, Journal of Chemical Thermodynamics 18 (1986) 739-760.

[14]W. Wagner, R. Kleinrahm, Metrologia 41 (2004) S24-S39.

[15]O. Kunz, W. Wagner, J. Chem. Engr. Data 57 (2012) 3032-3091.

[16]M.O. McLinden, C. Lösch-Will, J. Chem. Thermodyn. 39 (2007) 507-530.

[17]M. Richter, M.O. McLinden, J. Chem. Eng. Data 59 (2014) 4151-4164.

[18]M. Richter, M.O. McLinden, J. Chem. Thermodyn. (2015) (manuscript in preparation). 

(2007) 429-448.

[20]Landolt-Börnstein, Numerical Data and Functional Relationships in Science and Technology, New Series, II/16, Diamagnetic Susceptibility, Springer-Verlag, Heidelberg, 1986. [21]G.L. Harris, J.A. Torres, Selected laboratory and measurement practices and procedures, to support basic mass calibrations, National Institute of Standards and Technology, 2003. [22]O. Kunz, R. Klimeck, W. Wagner, M. Jaeschke, The GERG-2004 Wide-Range Equation of State for Natural Gases and Other Mixtures, GERG TM15, Fortschritt-Berichte VDI, 2007. [23]E.W. Lemmon, personal communication, NIST, 2015. [24]H. Kalra, D.B. Robinson, Cryogenics 15 (1975) 409-412. [25]J.E. Powers, E.A. Manker, A.E. Mather, V.F. Yesavage, Vapor-liquid equilibrium data for the methane-propane system, AIChE 65th National Meeting, May 4-7, 1969., 1969. [26]A.J.B. Cutler, J.A. Morrison, Trans. Faraday Soc. 61 (1965) 429-442. [27]J.G. Roof, J.D. Baron, J. Chem. Eng. Data 12 (1967) 292-293. [28]H.F. Stoeckli, L.A.K. Staveley, Helv. Chim. Acta 53 (1970) 1961-1964. [29]E.F. May, J.Y. Guo, J.H. Oakley, T.J. Hughes, B.F. Graham, K.N. Marsh, S.H. Huang, J. Chem. Engr. Data 60 (2015) 3606-3620. [30]L.A. Webster, A.J. Kidnay, J. Chem. Eng. Data 46 (2001) 759-764. [31]R.A. Price, R. Kobayashi, J. Chem. Eng. Data 4 (1959) 40-52. [32]B.H. Sage, W.N. Lacey, J.G. Schaafsma, Ind. Eng. Chem. 26 (1934) 214-217. [33]H.H. Reamer, B.H. Sage, W.N. Lacey, Ind. Eng. Chem. 42 (1950) 534-539. [34]M.O. McLinden, J.D. Splett, J. Res. Natl. Inst. Stand. Technol. 113 (2008) 29-67. [35]M.E. Wieser, N. Holden, T.B. Coplen, J.K. Böhlke, M. Berglund, W.A. Brand, P. De Bievre, M. Gröning, R.D. Loss, J. Meija, T. Hirata, T. Prohaska, R. Schoenberg, G. O'Connor, T. Walczyk, S. Yoneda, X. Zhu, Pure Appl. Chem. 85 (2013) 1047-1078. [36]P.T. Boggs, R.H. Byrd, J.R. Donaldson, R.B. Schnabel, ACM Trans. Math. Software 15 (1989) 348-364.

[37]H.C. Wiese, J. Jacobs, B.H. Sage, J. Chem. Eng. Data 15 (1970) 82-91.

[38]A.R. Price, Low temperature vapor-liquid equilibrium in light hydrocarbon mixtures: methane-ethane-propane system, Rice University, PhD Dissertation, 1957. [39]W.W. Akers, J.F. Burns, W.R. Fairchild, Ind. Eng. Chem. 46 (1954) 2531-2534. [40]J.C.G. Calado, G.A. Garcia, L.A.K. Staveley, J. Chem. Soc., Faraday Trans. 170 (1974) 1445-1451. [41]H. Cheung, D.I. Wang, Ind. Eng. Chem. Fundam. 3 (1964) 355-361. [42]J. Joffe, Ind. Eng. Chem. Fundam. 15 (1976) 298-304. [43]D.P.L. Poon, B.C.-Y. Lu, Adv. Cryo. Eng. 19 (1974) 292-299. [44]V.G. Skripka, I.E. Nikitina, L.A. Zhdanovich, A.G. Sirotin, O.A. Benyaminovich, Gazov. Promst. 15 (1970) 35-36. [45]I. Wichterle, R. Kobayashi, J. Chem. Eng. Data 17 (1972) 4-9. [46]G.M. Wilson, Adv. Cryo. Eng. 20 (1975) 164-171. [47]M.E. Kandil, K.N. Marsh, A.R.H. Goodwin, J. Chem. Thermodynamics 37 (2005) 684-691. 